\title{
ABD Finansal Piyasalarındaki Gelişmelerin ve Belirsizliklerin Borsa İstanbul Üzerindeki Asimetrik Etkileri
}

\section{The Asymmetric Effects of Developments and Uncertainties in US Financial Markets on Borsa Istanbul}

\author{
Barış Kocaarslan ${ }^{\mathrm{a}, *}$ \\ ${ }^{a}$ Dr. Arş. Gör., Yalova Üniversitesi, İktisadi ve İdari Bilimler Fakültesi, İşletme Bölümü, Yalova / Türkiye \\ ORCID: 0000-0003-4492-980X
}

\section{MAKALE BİLGİṠ \\ Makale Geçmişi: \\ Başvuru tarihi: 09 Eylül 2019 \\ Düzeltme tarihi: 03 Haziran 2020 \\ Kabul tarihi: 10 Haziran 2020}

\author{
Anahtar Kelimeler: \\ Borsa İstanbul (BIST) \\ Doğrusal Olmayan ARDL (NARDL) \\ ABD Finansal Piyasaları \\ Belirsizlik
}

ABD Merkez Bankası (FED)
ÖZ

$\mathrm{Bu}$ çalışmada, ABD hisse senedi piyasası ve bu piyasadaki belirsizliklerin yanında $\mathrm{ABD}$ Merkez Bankası (FED) para politikalarındaki belirsizliğin Borsa İstanbul (BIST) üzerindeki etkileri incelenmiştir. $\mathrm{Bu}$ incelemede, doğrusal olmayan otoregresif gecikmesi dağıtılmış (NARDL) ve doğrusal otoregresif gecikmesi dağıtılmış (ARDL) modellerinden faydalanılmıştır. Elde edilen sonuçlara göre, ABD hisse senedi piyasasındaki değişimlerin BIST üzerinde kısa dönemde pozitif ve uzun dönemde negatif etkilerinin olduğu ve bu etkilerin kisa dönemde asimetrik olduğu gözlemlenmiştir. Buna ek olarak, hem ABD hisse senedi piyasasındaki belirsizliğin hem de FED politikalarındaki belirsizliğin BIST üzerinde asimetrik etkilere sahip olduğu ve bu etkilerin kısa ve uzun dönemde önemli derecede farklı olduğu bulgusuna ulaşılmıştır. Bulgularımız etkin yatırım stratejileri uygulamak ve küresel risklere karşı uygun ekonomi politikalarının belirlenmesi açısından önemli çıkarımlar içermektedir.

\section{ARTICLE INFO}

\section{Article history:}

Received 09 September 2019

Received in revised form 03 June 2020

Accepted 10 June 2020

\section{Keywords:}

Borsa Istanbul (BIST)

Nonlinear ARDL (NARDL)

US Financial Markets

Uncertainty

Federal Reserve (FED)

\section{A B S T R A C T}

In this study, the effects of US stock market, US stock market uncertainty and the Federal Reserve's (FED) monetary policy uncertainty on Borsa Istanbul (BIST) are investigated. In this investigation, nonlinear and linear autoregressive distributed lag (NARDL and ARDL) models are used. It is observed that changes in US stock market have positive and negative impacts on the BIST in the short- and long-term, respectively, and these effects are asymmetric in the short-term. Furthermore, it is found that the uncertainties in the US stock market and the FED policies have different and asymmetric effects on the BIST in the shortand long-term. Our findings have important implications for implementing effective investment strategies and determining appropriate economic policies against global risks.

\section{Giriș}

Son yıllarda teknolojik altyapının gelişmesi, ekonomi politikalarındaki değişiklikler ve bunların neticesinde piyasalar arasındaki sermaye akımlarını önleyici kısıtların kaldırılması birbirinden farklı özellik gösteren global piyasaların bütünleşme eğilimi göstererek benzer global risklerden etkilenmelerine neden olmuştur. $\mathrm{Bu}$ gelişmelerin neticesinde, küreselleşen dünya ekonomisinde özellikle daha riskli olan gelişmekte olan ülkelerin hisse senedi piyasaları artan finansal liberalizasyon ile birlikte gelişmiş piyasalardaki dalgalanmalardan kaynaklanan risklere daha açık hale gelmektedir. Gelişmekte olan piyasaların daha fazla getiri ile birlikte daha riskli olan karakteristikleri yatırımcıların, politika yapıcıların ve araştırmacıların bu piyasalara olan ilgisini canlı tutmaktadır. Bu ilginin sonucu

\footnotetext{
* Sorumlu yazar/Corresponding author

e-posta: bariskocaarslan@gmail.com
} 
olarak gelişmekte olan piyasaların hangi global risklere açık olduğu ve bu risklerin hangi ekonomik mekanizmalar aracılığı ile bu piyasaları etkilediği meselesi literatürdeki tartışmaların odak noktasını oluşturmaktadır.

Uluslararası yatırımcıların temel amacı global piyasalarda oluşturdukları portföyleri çeşitlendirerek piyasaların yerel piyasalarda elimine edilemeyen risklerini (sistematik riskler) azaltmaya çalışmak ve bunun potansiyel faydalarından önemli miktarda getiriler elde etmektir (Solnik, 1974). Bunu başarmak için yatırımcılar zaman içinde getirileri benzer trendler sergilemeyen finansal varlıklardan oluşan portföyleri oluşturmayı amaçlar. Fakat piyasalar arasında artan finansal entegrasyon ile birlikte bu avantajdan yararlanmak gittikçe zorlaşmaktadır (Aloui vd., 2011). Bu açıdan bakıldığında, global piyasaları yönlendirici niteliğe sahip (ABD finansal piyasaları gibi) piyasalardaki gelişmelerin yapılan incelemelerde dikkate alınması önem arz etmektedir. Özellikle daha riskli olan gelişmekte olan piyasalara yatırım kararı bu piyasalardaki dalgalanmaların global piyasalardaki gelişmelerden kaynaklı nedenlerini araştırmayı gerektirmektedir. $\mathrm{Bu}$ gereklilik gelişmekte olan piyasaların temel karakteristiklerinin yönlendirici niteliklere sahip olan global piyasalardaki konjonktürel dalgalanmalar ve belirsizlikler ile olan bağını dikkate alma mecburiyetini beraberinde getirmektedir. Bunun yanında global piyasalarda risk iştahının azalmasına veya artmasına neden olan gelişmelerin dikkatle üzerinde durulması gerekmektedir (Kumar ve Persaud, 2002). Global piyasalardaki ekonomik ve politik şokların kısa ve uzun vadede yatırımcı kararlarını etkileyerek piyasalar arasındaki ilişkileri nasıl değiştireceği meselesi kapsamlı bir incelemeye tabi tutulmalıdır. $\mathrm{Bu}$ ilişkilerin doğasına dair detaylı incelemeler farklı risk profillerine sahip olan piyasa oyuncularına yatırım stratejilerini belirleme ve dolayısı ile portföylerinin içeriğini yeniden oluşturma bağlamında önemli bilgiler sunmaktadır.

$\mathrm{Bu}$ çalışmanın temel amacı Türkiye hisse senedi piyasasının (BIST) yatırım potansiyelini yeniden değerlendirmektir. Bu amaçla literatürde daha önce Türkiye hisse senedi piyasası üzerinde etkileri tartışılan ABD hisse senedi piyasasındaki gelişmeler ve belirsizliklerin etkileri güçlü ekonometrik metotlar kullanılarak yeniden gözden geçirildi. Son zamanlarda, global piyasalardaki fonlama sıkıntılarına FED politikalarındaki belirsizliğin neden olduğu konusu sıcak bir tartışma olarak güncelliğini korumaktadır. Buradan hareketle, literatürde daha önce dikkate alınmayan FED politikalarındaki belirsizliklerin BIST üzerindeki etkileri de incelenerek literatüre katkı sağlanması amaçlanmıştır. Makalenin ilerleyen bölümlerinde BIST üzerindeki etkisi değerlendirilen değişkenlerin neden global piyasalar için önemli olduğuna dair daha detaylı değerlendirmeler yapılmıştır.

Literatürdeki çalışmaların önemli bir çoğunluğu Türkiye hisse senedi piyasası ile global piyasalar arasındaki ilişkileri eşbütünleşme-nedensellik açısından değerlendirmişlerdir. $\mathrm{Bu}$ çalışmalarda genellikle doğrusal modeller kullanılarak piyasalar arasındaki simetrik etkiler incelenmiştir. Fakat, ekonomi ve finans literatüründeki bazı teorik ve ampirik incelemelerde makroekonomik değişkenler ve finansal piyasalar arasında doğrusal olmayan asimetrik ilişkilerin olabileceği ifade edilmiştir (Kahneman ve Tversky, 1979;
Acemoglu ve Scott, 1997; Shin vd., 2014). Bu olasiliktan dolayı sadece doğrusal modeller kullanılarak yapılan analizler yanıltıcı bulgulara ulaşmamıza neden olabilmektedir. Bu bilgilerin ışığında, çalışmamızda BIST ve onun belirleyicileri arasındaki ilişkileri incelemek amaciyla doğrusal olmayan otoregresif gecikmesi dağıtılmış (NARDL) ve doğrusal otoregresif gecikmesi dağıtılmış (ARDL) modelleri kullanılmıştır. Bu analizler BIST üzerinde etkisi olan faktörlerdeki pozitif ve negatif değişikliklerin etkilerinin kısa ve uzun dönemde farklılaşıp farklılaşmadığını dikkate alan çalışma bulunmaması nedeniyle literatüre önemli bir katkı sunmaktadır.

\section{Literatür İncelemesi}

\subsection{ABD Hisse Senedi Piyasas1 ve Global Piyasalar}

Global piyasalar arasındaki karşılıklı bağımlılığın temel nedenleri literatürdeki önemli çalışmalar tarafindan incelenmiştir (Bekaert ve Harvey, 1995; Carrieri vd., 2007). $\mathrm{Bu}$ çalışmaların büyük bir çoğunluğu piyasalar arasındaki entegrasyon derecesinin zamanla değişiminin muhtemel sebeplerini farklı ekonometrik yöntemler kullanarak sorgulamışlardır. ABD finansal piyasalarının diğer global piyasalar üzerindeki yönlendirici etkisi literatürdeki önemli çalışmalarda vurgulanmıştır. (Chowdhury, 1994; Bessler ve Yang, 2003; Olgun ve Ozdemir, 2008). Bu bağlamda, ABD piyasalarındaki dalgalanmaların ve belirsizliklerin özellikle gelişmekte olan piyasaları etkilemedeki anahtar rolünü incelemek bu piyasaların yatırım potansiyelini değerlendirme açısından büyük bir öneme sahiptir. Global piyasalardaki portföy çeşitlendirme firsatlarını değerlendirebilmek için öncelikle ABD hisse senedi piyasasının etkileri göz önünde bulundurulmalıdır.

ABD hisse senedi piyasasının Türkiye hisse senedi piyasası üzerindeki etkileri literatürdeki bazı çalışmalar tarafından incelenmiştir. Küçükkaya (2009), Toda-Yamamoto (1995) prosederünü kullanarak $\mathrm{ABD}$ ve Türkiye hisse senedi piyasaları arasındaki Granger nedensellik ilişkisini araştırmıştır. $\mathrm{Bu}$ çalışmanın bulguları ABD piyasasındaki gelişmelerin Türkiye hisse senedi piyasasındaki çeşitlendirme firsatlarını kısıtlayacağını işaret etmektedir. Zeren ve Koç (2013), Maki (2012) koentegrasyon testini uygulayarak Türkiye ile ABD hisse senedi piyasaları arasında eşbütünleşme ilişkisi olduğunu göstermiştir. Kocaarslan vd. (2017) Toda-Yamamoto (1995) Granger nedensellik testini kullanarak ABD hisse senedi piyasasının hem gelişmiş piyasalar hem de gelişmekte olan Türkiye ve Rusya hisse senedi piyasaları üzerindeki önemli derecedeki etkisine dair kanıtlar sunmuştur. Sadeghzadeh ve Elmas (2018) Panel ARDL yönteminden faydalanarak ABD hisse senedi endeksindeki (S\&P 500) artışların BIST getirileri üzerinde kısa dönemde pozitif, uzun dönemde ise negatif etkileri olduğunu göstermişlerdir. Karğın vd. (2018) S\&P 500 endeksinin Almanya ve Fransa hisse senedi piyasalarına kıyasla BIST üzerindeki en etkili endeks olduğu sonucuna ulaşmışlardır. Tüm bu bulguların ışı̆̆ında, yapilan analizlerde, BIST hisse senetleri getirilerindeki değişimlerin kaynağını araştırırken ABD hisse senedi piyasasındaki dalgalanmalar dikkate alınmıştır. 


\subsection{ABD Hisse Senedi Piyasasındaki Belirsizlikler ve Global Piyasalar}

Opsiyon piyasalarındaki fiyat dalgalanmaları dikkate alınarak oluşturulan zımni volatilite endeksleri gelecekte ortaya çıkabilecek fiyat oynaklıkları ve dolayısıyla belirsizlikler ile ilgili piyasa oyuncularına bir fikir vermektedir. Buradan hareketle zimni volatilite endekslerindeki dalgalanmaların bugünkü piyasalar üzerinde önemli etki potansiyeline sahip olacağı iddia edilebilir. Literatürdeki birçok çalışma bu iddiayı destekler nitelikte bulgular sunmuştur. Chicago Opsiyon Borsası verilerinden elde edilen VIX endeksi ABD piyasaları için zımni volatilite endeksini temsil etmektedir. $\mathrm{Bu}$ endeks hisse senedi piyasalarındaki belirsizliği temsilen kullanılacak en önemli göstergelerden biridir (Bloom, 2014). VIX endeksinin ABD hisse senedi piyasasındaki getiriler ve volatilite üzerindeki dikkate değer etkisi bazı çalışmalar tarafindan ortaya çıkarılmıştır (Blair vd., 2001; Ang vd., 2006; Becker vd., 2009). Global piyasaların ABD piyasalarındaki gelişmelerden güçlü bir şekilde etkilenebileceğinden önceki bölümde bahsetmiştik. Dolayısı ile VIX endeksindeki dalgalanmaların global piyasalara yansıma ihtimali oldukça yüksektir.

VIX endeksi ile BIST arasındaki ilişkileri inceleyen bazı çalışmalar literatürde mevcuttur. Korkmaz ve Çevik (2009) Türkiye hisse senedi piyasasının da içinde olduğu bazı gelişmekte olan piyasalardaki volatilitenin VIX'deki dalgalanmalardan güçlü bir şekilde etkilendiğini bulmuşlardır. Kaya (2015) BIST ile VIX endeksi arasında eşbütünleşme olduğunu ve vektör hata düzeltme modelini kullanarak VIX endeksinin BIST üzerinde önemli bir etkisi olduğunu göstermiştir. Bu bulguya benzer bir bulgu, Hatipoğlu ve Tekin (2017) tarafindan kuantil regresyon yöntemi uygulanarak elde edilmiştir. Öner vd. (2018) Granger nedensellik testlerini kullanarak VIX endeksinden BIST endeksine yönelik tek yönlü bir ilişkinin olduğu sonucuna varmışlardır. Bu bulguyu destekleyecek şekilde, frekans alanı nedensellik analizi kullanarak, Başarır (2018) VIX endeksinden BIST endeksine yönelik hem kalıcı hem de geçici nedensellik ilişkisini belgelendirmiştir. Sadeghzadeh ve Elmas (2018) Panel ARDL yöntemini kullanarak BIST endeksini etkileyen global faktörler arasında en önemlilerinden birinin VIX endeksi olduğuna dair kanıtlar sunmuştur. Literatürün ortaya koyduğu iddiaları ve bulguları dikkate alarak analizlerimizde VIX endeksindeki gelişmelerin BIST getirileri üzerinde oynayacağı rol incelenmiştir.

\subsection{ABD Merkez Bankası (FED) Politikalarındaki Belirsizlikler ve Global Piyasalar}

Baker vd. (2016) ekonomi politikalarındaki belirsizliklerin hisse senedi piyasasındaki volatiliteyi arttırıp yatırımlar üzerinde negatif bir etki yarattığını köşetaşı niteliğindeki çalışmalarında göstermişlerdir. Ekonomi politikalarındaki belirsizliklerin en önemli bileşenlerinden biri olarak ABD Merkez Bankasının para politikasındaki belirsizlikler ön plana çıkmaktadır (Baker vd., 2016).

Daha önce de belirttiğimiz gibi global piyasalardaki ABD finansal piyasalarının etkisi düşünüldüğünde $\mathrm{ABD}$ merkez bankası (FED) politikalarındaki belirsizliklerin piyasalar arasındaki etkileşimi güçlü bir şekilde etkileyebileceği ihtimali gözardı edilmemelidir. Özellikle dıș piyasalardan gelen fon akışına ihtiyacı olan Türkiye gibi gelişmekte olan ülkelerin riskli piyasalarından elde edilen getiriler üzerinde bu belirsizliklerin önemli bir rol oynayabileceği ihtimali son derece güçlüdür. Son yıllarda, Türkiye finansal piyasaları FED'in gelecekte para politikasında (daraltıcı veya genişletici para politikası) yapacağı değişikliklerdeki belirsizliklerin yarattığı global yatırımcılara endişe veren yatırım ikliminin negatif etkilerini tecrübe etmiştir. Bu para politikası belirsizliklerinden kaynaklanan BIST hisse senedi getirilerindeki dalgalanmalar literatürde daha önce güçlü ekonometrik yöntemler kullanılarak kapsamlı bir incelemeye konu olmamıştır. Bu nedenle, bu çalışmada FED'in politikalarındaki belirsizliklerin BIST getirileri üzerindeki etkilerinin karakteristiği test edilerek literatüre önemli bir katkı sağlanması amaçlanmıştır.

\section{Veri Seti ve Ekonometrik Yöntem}

\subsection{Veri}

Morgan Stanley Capital Information (MSCI) hisse senedi piyasası endeksleri global piyasaları en iyi şekilde temsil ettikleri düşünüldüğünden literatürde en fazla tercih edilen endeksler arasındadır (Fong vd., 2005). Bu nedenle çalışmamızda ABD ve Türkiye hisse senedi piyasaları ile ilgili endeks verilerini temsilen bu piyasalar için hazırlanan MSCI endeksleri kullanılmıştır. Dolar üzerinden elde edilen getiriler global yatırımcılar için daha önemli olduğu için kullandığımız hisse senedi piyasası endeks verileri dolar cinsinden ifade edilen serilerden elde edilen verilerdir (Cho vd., 1986).

ABD hisse senedi piyasasındaki belirsizlikleri temsilen ilgili literatürde en fazla tercih edilen ve Chicago Board Options Exchange (CBOE) tarafindan S\&P 500 endeks opsiyonlarından faydalanılarak zımni volatiliteyi ölçmek için hazırlanan VIX endeksi kullanılmıştır (Bloom, 2014). $\mathrm{Bu}$ endeks aynı zamanda korku endeksi olarak da bilinmektedir. ABD para politikası belirsizliklerini temsilen ise yine Chicago Board Options Exchange (CBOE) tarafindan hesaplanan TYVIX (10-year U.S. Treasury Note Volatility Index) endeksi kullanılmıştır. $\mathrm{Bu}$ endeks hesaplanırken VIX endeksi oluşturulurken kullanılan prosedür takip edilir ve SP\&500 endeks opsiyonları yerine 10 yıllık hazine tahvili vadeli işlemleri üzerine olan opsiyonlar dikkate alınır. Bu bağlamda, TYVIX endeksi tahvil piyasalarındaki beklenen volatilite ve dolayısı ile para politikası belirsizliği üzerine önemli bilgiler içerir. Örneğin, ABD Merkez Bankası (FED) Federal Açık Piyasa Komitesi açıklaması öncesinde bu endeks değerleri artış eğilimine girer ve dolayısıyla açıklanma ihtimali olan para politikaları ile ilgili belirsizliğin makroekonomik etkilerine dair bilgi içerir (CBOE, 2015). Yukarıda açıklanan argümanlardan dolayı FED politikalarındaki belirsizliklerden kaynaklanan makroekonomik etkileri ölçmek için TYVIX endeksi kullanılmıştır.

Çalışmada kullanılan endekslere ait günlük veri setleri kullanılmıştır. Analizler için seçtiğimiz periyot 03/01/2011 ve 30/01/2019 tarihleri arasındaki zaman aralığını kapsamaktadır. Global kriz sonrası yeniden şekillenen uluslararası finansal sistem, değişen yatırımcı algısı ve bunların sonucunda farklılaşan piyasalar arasındaki 
ilişkilere odaklanmak için bu çalışmada kriz sonrası periyoda odaklanılmıştır (Hoffmann vd., 2013).

\subsection{Yöntem}

Çalışmanın amacını gerçekleştirmek ve analizlerin ortaya çıkardığı bulguları doğru yorumlayabilmek için literatürde ön plana çıkan güçlü zaman serisi yöntemlerinden faydalanılmıştır. Çalışmada daha önce bahsedildiği gibi, ABD hisse senedi piyasası ve bu piyasadaki belirsizliklerin yanında ABD merkez bankası (FED) para politikasındaki belirsizliğin Türkiye hisse senedi piyasası (Borsa İstanbul) üzerindeki etkilerinin ARDL ve NARDL modelleri kullanılarak incelenmesi amaçlanmıştır. $\mathrm{Bu}$ bölümde bu modellerin prosedürü genel hatlarıyla izah edilip literatürdeki diğer modellere kıyasla avantajlarından bahsedildi.

İlgilenilen uzun dönemli doğrusal ilişkilerin tespit edilebilmesi için doğrusal otoregresif gecikmesi dağıtılmış (ARDL) modeli kullanılmıştır (Pesaran ve Shin, 1998; Pesaran vd., 2001). ARDL modelini kullanmanın en önemli avantajlarından biri, analizlerde kullanılan değişkenlerin durağanlık derecelerinin farklılaşmasına bakılmaksızın (I(1) veya $\mathrm{I}(0)$ ) uygulanabilmesidir (Pesaran vd., 2001). ARDL modeli değişkenler arasındaki kısa ve uzun dönemdeki dinamik etkileşimlerin sınırsız bir hata düzeltme modeli (unrestricted error correction model) kullanarak ve otokorelasyon sorununu önemli oranda azaltarak incelenmesine imkan verir. Çalışmada ARDL yaklaşımından faydalanılarak oluşturulan hata düzeltme modeli aşağıda gösterilmiştir.

$$
\begin{aligned}
& \Delta \text { LTUR }_{t}=\mu+\alpha_{1} \text { LTUR }_{t-1}+\alpha_{2} \text { LUSA }_{t-1}+\alpha_{3} \text { LVIX }_{t-1}+ \\
& \alpha_{4} \text { LTYVIX }_{t-1}+\sum_{i=1}^{p-1} \lambda_{1} \Delta L T U R_{t-i}+\sum_{i=0}^{q-1} \lambda_{2} \Delta L U S A_{t-i}+ \\
& \sum_{i=0}^{q-1} \lambda_{3} \Delta L V I X_{t-i}+\sum_{i=0}^{q-1} \lambda_{4} \Delta L T Y V I X_{t-i}+\psi t+\varepsilon_{t}
\end{aligned}
$$

Yukarıdaki regresyon denklemi kullanılarak ilgilenilen değişkenler arasındaki eşbütünleşme ilişkisi tahmin edilmiştir. $\mu$ ve t sırasıyla sabit ve trend unsurlarını temsil eder. LTUR, LUSA, LVIX ve LTYVIX değişkenleri sırasıyla çalışmamızda kullanılan Türkiye ve ABD hisse senedi piyasaları endeksleri ile VIX ve TYVIX endekslerinin logaritmik olarak ifade edilmiş formunu temsil etmektedir. Değişkenlerin logaritmaları alınarak modele dahil edilmesi kullanılan endeks değerleri arasında tutarlılık sağlanmasına yardımcı olur. $\Delta$ sembolü değişkenlerin birinci farklarını belirten operatörü temsil eder. $\lambda_{1}, \lambda_{2}, \lambda_{3}$ ve $\lambda_{4}$ kaysayıları modelin degişkenler için tahmin edilen kısa dönemdeki etkiler ile ilgili katsayılarını temsil ederken, $\alpha_{1}, \alpha_{2}, \alpha_{3}$, ve $\alpha_{4}$ katsayıları ilgili değişkenler için tahmin edilen uzun dönem katsayılarını temsil eder. Eşbütünleşme ilişkisinin varlığını incelemek amacıyla ARDL sınır testi için geliştirilen prosedür takip edilerek temel hipotez olan $\mathrm{H}_{0:} \alpha_{1}=\alpha_{2}=\alpha_{3}=\alpha_{4}=0$ hipotezini test etmek için F-test istatistiği kullanılır.

İlgili literatürdeki bazı önemli çalışmalar (Schorderet, 2003; Granger ve Yoon, 2002) etkisi incelenen değişkenlerdeki pozitif ve negatif dalgalanmalar ayrı ayrı dikkate alındığında incelenen eşbütünleşme ilişkilerinin ve bağımsız değișkenlerin bağımlı değișken üzerindeki etkilerinin farklılaşacağına dair kanıtlar sunmuşlardır. Bu durum asimetrik etkiler dikkate alınmadığı zaman değişkenler arasındaki gizli bir eşbütünleşme ilişkisinin varlığının gözden kaçırılmasına neden olabilir. Değişkenler arasında doğrusal olmayan etkileşimler mevcut ise doğrusal modeller kullanılarak yapılan analizler ilişkilerin doğası ile ilgili yanlış çıkarımlarda bulunmamıza neden olabilir. Bu olasılığı elimine edebilmek için literatürde öne çıkan doğrusal olmayan modellerden faydalanmamız gerekmektedir. Doğrusal olmayan ilişkilerin tespit edilebilmesi, elde edilen analiz sonuçlarını karşılaştırabilmek ve bu sonuçlara dayalı doğru çıkarımlarda bulunabilmek için ARDL modelinin doğrusal olmayan ilişkileri incelemek amacıyla geliştirilmiş bir versiyonu olan doğrusal olmayan (nonlinear) otoregresif gecikmesi dağıtılmış (NARDL) modeli kullanılmıştır (Shin vd., 2014). NARDL modelinin diğer doğrusal olmayan modellerin tahmin yapma prosedüründe fazla sayıda parametre içermesinden kaynaklanan problemleri gibi zayıflıkları yoktur. $\mathrm{Bu}$ açıdan diğer modellere kıyasla oldukça güçlü olduğu iddia edilebilir. Çalışmanın ana temasını oluşturan NARDL modeli aşağıda detaylı bir anlatımla izah edilmiştir. NARDL modeli denkleminin kapalı formu aşağıdaki biçimdedir

$$
\operatorname{LTUR}_{t}=\alpha_{0}+\alpha_{1}\left(\operatorname{LUSA}_{t}\right)+\alpha_{2}\left(\operatorname{LVIX}_{t}\right)+\alpha_{3}\left(L T Y V I X_{t}\right)+\mu_{t}
$$

Yukarıda kapalı formu verilmiş eşitlik kullanılarak modele ait doğrusal olmayan form aşağıdaki denklemde ifade edilmiştir.

$L T U R_{t}=\beta_{0}+\beta_{1}\left(L U S A_{t}^{-}\right)+\beta_{2}\left(L U S A_{t}^{+}\right)+\beta_{3}\left(L V I X_{t}^{-}\right)+$ $\beta_{4}\left(L V I X_{t}^{+}\right)+\beta_{5}\left(L T Y V I X_{t}^{-}\right)+\beta_{6}\left(L T Y V I X_{t}^{+}\right)+\mu_{t}$

Denklemde, $\beta_{1}, \ldots, \beta_{6}$ modele ait uzun dönem etkileri gösteren parametrelerdir. Ayrıca, $L U S A_{t}^{-}, L U S A_{t}^{+}, L V I X_{t}^{-}$, LVIX ${ }_{t}^{+}, \quad$ LTYVIXX - ve LTYVIX ${ }_{t}^{+}$modelde yer alan değişkenlerin negatif ve pozitif asimetrik etkilerini göstermektedir.

Shin vd. (2014)'nin uyguladığı prosedür takip edilerek, aşağıdaki asimetrik eşbütünleşme regresyonu dikkate alınd.

$$
y_{t}=\beta^{+} x_{t}^{+}+\beta^{-} x_{t}^{-}+u_{t}
$$

Burada $\beta^{+}$ve $\beta^{-}$uzun dönem parametrelerini temsil etmektedir. $x_{t} \mathrm{k}^{*} 1$ vektörüdür ve $x_{t}=x_{0+} x_{t}^{+}+x_{t}^{-}$ile ifade edilmektedir. NARDL modeli dışsal değişkenlerin aşağıda gösterilen negatif ve pozitif kısmi ayrıştırmaları toplamlarını dikkate almaktadır (Shin vd., 2014).

$$
\begin{aligned}
& x_{t}{ }^{+}=\sum_{i=1}^{t} \Delta x_{i}{ }^{+}=\sum_{i=1}^{t} \max \left(\Delta x_{i}, 0\right) \\
& x_{t}{ }^{-}=\sum_{i=1}^{t} \Delta x_{i}{ }^{-}=\sum_{i=1}^{t} \min \left(\Delta x_{i}, 0\right)
\end{aligned}
$$

Buradan hareketle asimetrik etkisi test edilen her bir değişkene ait pozitif ve negatif değişimlerin kısmi toplam süreçleri $L U S A_{t}^{-}, L U S A_{t}^{+}, L V I X_{t}^{-}, L V I X_{t}^{+}, L T Y V I X_{t}^{-}$ve $L T Y V I X_{t}^{+}$aşağıdaki gibi ifade edilir. 
$\operatorname{LUSA}_{t}^{+}=\sum_{i=1}^{t} \Delta L U S A_{i}^{+}=\sum_{i=1}^{t} \max \left(\Delta \operatorname{LUSA}_{i}, 0\right)$
$\operatorname{LUSA}_{t}^{-}=\sum_{i=1}^{t} \Delta L U S A_{i}^{-}=\sum_{i=1}^{t} \min \left(\Delta L U S A_{i}, 0\right)$
$\operatorname{LVIX}_{t}^{+}=\sum_{i=1}^{t} \Delta L V I X_{i}^{+}=\sum_{i=1}^{t} \max \left(\Delta L V I X_{i}, 0\right)$
$\operatorname{LVIX}_{t}^{-}=\sum_{i=1}^{t} \Delta L V I X_{i}^{-}=\sum_{i=1}^{t} \min \left(\Delta L V I X_{i}, 0\right)$
$\operatorname{LTYVIX}_{t}^{+}=\sum_{i=1}^{t} \Delta \operatorname{LTYVIX}_{i}^{+}=\sum_{i=1}^{t} \max \left(\operatorname{LTYVIX}_{i}, 0\right)(11)$
$\operatorname{LTYVIX}_{t}^{-}=\sum_{i=1}^{t} \Delta \operatorname{LTYVIX}_{i}^{-}=\sum_{i=1}^{t} \min \left(\operatorname{LLTVIX}_{i}, 0\right)$

Doğrusal ARDL modelinin asimetrik etkileri içeren geliştirilmiş versiyonu olan NARDL modelinin gösterimi aşă̆ıdaki gibidir:

$$
\begin{aligned}
& \Delta L T U R_{t}=\mu+\chi \operatorname{LTUR}_{t-1}+\omega_{1}^{+} \operatorname{LUSA}_{t-1}{ }^{+}+\omega_{1}^{-} \operatorname{LUSA}_{t-1}{ }^{-}+\omega_{2}^{+} \operatorname{LVIX}_{t-1}^{+}+ \\
& \omega_{2}{ }^{-}{ } V_{X}{ }_{t-1}{ }^{-}+\omega_{3}{ }^{+} \text {LTYVIX }_{t-1}{ }^{+}+\omega_{3}{ }^{-} \text {LTYVIX }_{t-1}{ }^{-}+\sum_{i=1}^{p-1} \tau \Delta \operatorname{LTUR}_{t-i}+ \\
& \sum_{i=0}^{q-1} \varphi_{1}{ }^{+} \Delta L U S A_{t-i}{ }^{+}+\sum_{i=0}^{q-1} \varphi_{1}{ }^{-} \Delta L U S A_{t-i}{ }^{-}+\sum_{i=0}^{q-1} \varphi_{2}^{+} \Delta L V I X_{t-i}{ }^{+}+\sum_{i=0}^{q-1} \varphi_{2}{ }^{-} \Delta L V I X_{t-i}{ }^{-}+ \\
& \sum_{i=0}^{q-1} \varphi_{3}^{+} \Delta L T_{Y V I X}{ }_{t-i}^{+}+\sum_{i=0}^{q-1} \varphi_{3}^{-} \Delta L \operatorname{TYVIX}_{t-i}^{-}+\psi t+\varepsilon_{t}
\end{aligned}
$$

Doğrusal modeldeki sınır testi prosedürüne benzer şekilde, eşbütünleşme ilişkisini araştırmak için temel hipotez olan $\mathrm{H}_{0:} \chi^{=} \omega_{1}^{+}=\omega_{1}^{-}=\omega_{2}{ }^{+}=\omega_{2}{ }^{-}=\omega_{3}{ }^{+}=\omega_{3}{ }^{-}=0$ hipotezi F-test istatistiği kullanılarak test edilir. Bir sonraki adımda, standart Wald testi kullanılarak kısa ve uzun dönemde simetri olup olmadığı incelenir. Uzun dönemde ve kısa dönemde simetrinin varlığını test edebilmek amacıyla sırayla uzun dönem için $\beta^{+}\left(-\omega_{j}^{+} / \chi\right)=\beta^{-}\left(-\omega_{j}^{-} / \chi\right)$ ve kısa dönem için $\sum_{i=0}^{q-1} \varphi_{j}^{+}=\sum_{i=0}^{q-1} \varphi_{j}^{-}$temel hipotezleri tüm $\mathrm{j}=1,2$, ve 3 için test edilir. Bir sonraki bölümde analizlerin ortaya çıkardığı ampirik bulgular sunulmuştur.

\section{Ampirik Bulgular}

\subsection{Birim Kök Test Sonuçları}

Doğrusal otoregresif gecikmesi dağıtılmış (ARDL) ve doğrusal olmayan otoregresif gecikmesi dağıtılmış (NARDL) yaklaşımlarımdan faydalanabilmek için kullanılan zaman serilerinin düzeyde veya birinci farklarında .durağan olmaları gerekmektedir (Pesaran ve Shin, 1998; Pesaran vd., 2001; Shin vd., 2014). Çalışmada kullanılan serilerin durağanlık derecesinin tespit edilebilmesi için Phillips-Perron (1988) (PP) ve Augmented Dickey-Fuller (1979) (ADF) birim kök testleri kullanılmıştır. Bu testler sadece sabit ve hem sabit hem de trendin ikisi bir arada dikkate alınarak kullanılan modellerde uygulanmıştır. Birim kök test sonuçları Tablo 1'de sunulmuştur. Birim kök test sonuçları değişkenlerin düzeyde veya birinci farklarında durağan olduklarını önermektedir. Bu bulgulara dayanarak ARDL ve NARDL modellerini kullanıp analizlerimize devam etmemizde herhangi bir sakınca görünmemektedir.
Tablo 1. Birim Kök Test Sonuçları

\begin{tabular}{cccc}
\hline & & ADF & PP \\
& & Testi & Testi \\
\hline LTUR & Sabit & -1.581701 & -1.621462 \\
LUSA & & -0.994308 & -0.89489 \\
LVIX & & $-6.174661 * * *$ & $-5.498097 * * *$ \\
LTYVIX & & $-4.961448^{* * * *}$ & $-4.283055^{* * *}$ \\
& & & \\
DLTUR & Sabit & $-43.78010^{* * *}$ & $-43.76574 * * *$ \\
DLUSA & & $-46.94257^{* * *}$ & $-47.69156^{* * *}$ \\
DLVIX & & $-48.01429 * * *$ & $-56.46743^{* * *}$ \\
DLTYVIX & & $-47.27816^{* * * *}$ & $-56.09051^{* * *}$ \\
\hline & & ADF & PP \\
& & Testi & Testi \\
\hline LTUR & Sabit & -2.597734 & -2.678265 \\
LUSA & ve Trend & -3.40907 & -3.077679 \\
LVIX & & $-6.673201 * * *$ & $-6.063392^{* * *}$ \\
LTYVIX & & $-6.232496^{* * * *}$ & $-5.774780^{* * *}$ \\
& & & \\
DLTUR & Sabit & $-43.76954 * * *$ & $-43.75499 * * *$ \\
DLUSA & ve Trend & $-46.93210^{* * * *}$ & $-47.68247 * * *$ \\
DLVIX & & $-48.00276^{* * * *}$ & $-56.47011^{* * * *}$ \\
DLTYVIX & & $-47.26690^{* * * *}$ & $-56.09698^{* * * *}$ \\
\hline
\end{tabular}

Not: D ve L sırasıyla değişkenlerin birinci farklarını ve log operatörlerini temsil etmektedir. Üstsimge $* * * \quad \% \quad 1$ düzeyinde anlamllı göstermektedir. ADF ve PP sirasiyla Augmented Dickey-Fuller ve Phillips-Perron testlerini ifade etmektedir.

\subsection{ARDL ve NARDL Modelleri Test Sonuçları}

Bu bölümde ARDL ve NARDL modelleri kullanılarak elde edilen ampirik test bulguları sunulmuştur. İlk olarak, önceki bölümlerde ifade edilen modeller kullanılarak çalışmanın amacını gerçekleştirebilmek için eşbütünleşme ilişkileri incelenmiştir. Maksimum gecikme (lag) uzunluğu seçimi literatürdeki çalışmalarda analizi yapılan gözlem sayısına bağlı olarak değişir. Bu çalışmadaki gibi günlük (veya aylık) veri kullanan çalışmalarda gözlem sayısı yıllık ve çeyreklik veri setlerine göre daha fazla olduğundan gecikme uzunluğu genelde 8-12 arasında belirlenmektedir (örn. Eren ve Başar, 2016). Önceki bölümlerde sunulan sınırsız hata düzeltme modellerindeki değişkenlerin gecikme uzunluklarının tespit edilebilmesi için maksimum gecikme (lag) uzunluğu bu çalışmada 12 olarak kabul edilmiş ve optimum gecikme uzunluğunu belirlemek için Akaike bilgi kriteri kullanılmıştır. İncelenen modellerin sağlamlığını tespit edebilmek amacıyla bazı tanılayıcı ve kararlılık testleri uygulanmıştır. Uygulanan modellerde değişen varyans problemi haricinde herhangi bir problem tespit edilmemiştir. Tanılayıcı ve kararlılık testlerinin sonuçları Tablo 2'de raporlanmıştır. Breusch-Godfrey LM, Breusch-Pagan-Godfrey ve Jarque-Bera testleri sirasiyla seri korelasyonu, değişen varyansı ve normallik varsayımını test etmek için kullanılmıştır. Model spesifikasyonu ve 
kararlılı̆̆ını test etmek için Ramsey RESET, CUSUM ve CUSUM of Squares testlerinden faydalanılmıştır. BreuschGodfrey LM ve Ramsey RESET test sonuçları modelde seri korelasyon, spesifikasyon ve kararlılık problemi olmadığını göstermektedir. Breusch-Pagan-Godfrey ve Jarque-Bera test sonuçları ise değişen varyans sorununa ve normal dağılıma uyulmadığı problemine işaret etmektedir. CUSUM ve CUSUM of Squares testleri ile Ramsey RESET test sonuçları arasındaki modelin stabil olup olmadığına dair farklı sonuçlar diğer sonuçlar ile birlikte değerlendirildiğinde modeldeki asıl problemin değişen varyanstan kaynaklandığını göstermektedir. Değişen varyanstan kaynaklanan etkin olmayan tahminlemeyi düzeltip daha kesin tahminler sağlamak amaciyla tahmin edilen katsayılar için Newey-West (1987) tahmincisi kullanılarak standart hata ve t-istatistik sonuçları sunulmuştur.

Tablo 2. Tanılayıcı ve Kararlılık Testleri Sonuçları

\begin{tabular}{ccc}
\hline BG Test & BPG Test & JB Test \\
\hline 0.107487 & $3.434283^{* * *}$ & $2385.9 * * *$ \\
\hline Ramsey RESET & CUSUM & CUSUM of Squares \\
\hline 1.023478 & Stabil Değil & Stabil Değil \\
\hline
\end{tabular}

Not: Tablo 2 tanılayıcı ve kararlılık test sonuçlarını sunmaktadır. BG, BPG ve JB sirasiyla Breusch-Godfrey LM, Breusch-Pagan-Godfrey ve JarqueBera testlerini temsil etmektedir. Üstsimge *** \% 1 düzeyinde anlamlılığ göstermektedir.

Yöntem bölümünde bahsedilen sınır testi için geliştirilen prosedür takip edilerek değişkenler arasındaki eşbütünleşme ilişkisinin varlığını incelemek amacıyla hesaplanan F-test istatistiği Tablo 3'de sirasiyla ARDL modeli için Panel A ve NARDL modeli için Panel B'de sunulmuştur. Hesaplanan F-test istatistik değerleri alt-sınır kritik değerden küçükse eşbütünleşme ilişkisinin olmadığı sonucuna ulaşılır. Eğer F-test istatistik değerleri alt-üst sınır kritik değerleri arasında yer alıyorsa eşbütünleşme ilişkisinin yokluğu veya varlığına ilişkin bir sonuca ulaşılamaz. F-test istatistik değerleri üst-sınır kritik değerden büyükse eşbütünleşme ilişkisinin varlığı ortaya konmuş olur. Panel A'da sunulan F-test istatistik değeri incelenen eşbütünleşme ilişkisinin doğrusal olmadığı sonucunu gösterir. Diğer taraftan Panel B'de sunulan F-test istatistik değeri Türkiye hisse senedi piyasası ve diğer açıklayıcı değişkenler arasında (ABD hisse senedi piyasası ve bu piyasadaki belirsizlikler ile ABD Merkez Bankası (FED) para politikasındaki belirsizlik) doğrusal olmayan eşbütünleşme ilişkisinin varlığını açık bir şekilde ortaya koyar. Bu sonuçlar bize değişkenler arasındaki ilişkilerin gerçek doğasını açığa çıkarabilmek için asimetrik etkilerin dikkate alınması gerekliliğini net bir şekilde göstermektedir.
Tablo 3. Sınır Testi Sonuçları

\begin{tabular}{|c|c|}
\hline \multicolumn{2}{|l|}{ Panel A. ARDL Modeli İçin F-test Sonuçları } \\
\hline Eşbütünleşme Hipotezi & F İstatistiği \\
\hline $\mathrm{F}\left(\mathrm{LTUR}_{\mathrm{t}} / \mathrm{LUSA}_{\mathrm{t}}, \mathrm{LVIX}_{\mathrm{t}} \mathrm{LTYVIX}_{\mathrm{t}}\right)$ & 3.275295 \\
\hline \multicolumn{2}{|c|}{ Panel B. NARDL Modeli İçin F-test Sonuçları } \\
\hline Eşbütünleşme Hipotezi & F İstatistiği \\
\hline 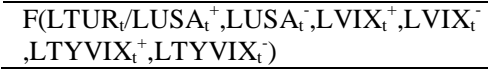 & $4.041444 * *$ \\
\hline \multicolumn{2}{|c|}{ 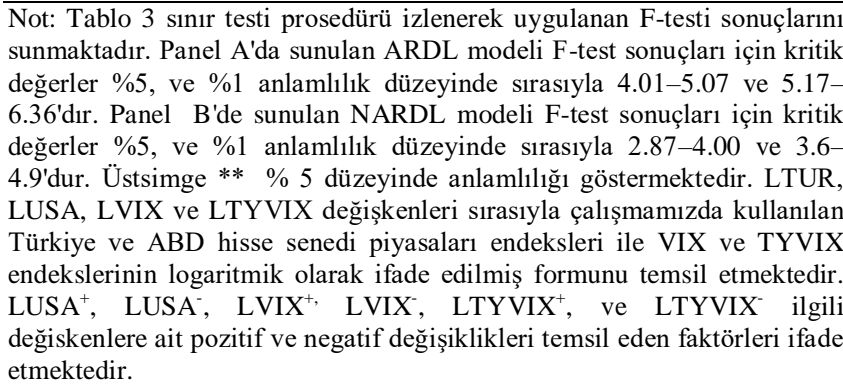 } \\
\hline
\end{tabular}

Eşbütünleşme ilişkisi doğrusal olmayan ARDL modelinde (NARDL) ortaya konduğu için Tablo 4'te NARDL modeli kullanılarak elde edilen kısa ve uzun dönemdeki dinamik ve asimetrik etkileşimleri gösteren tahmin sonuçları sunulmuştur. Tablo 5' te ise uzun dönemde ve kısa dönemde simetrinin varlığını test edebilmek amacıyla uygulanılan standart Wald-test sonuçları yer almaktadır. Bulguları yorumlamaya geçmeden kısaca pozitif ve negatif katsayıların nasıl yorumlanması gerektiğine dair kısa bir açıklama yapmak faydalı olacaktır. İlgili açıklayıcı değişkendeki pozitif değişimlerin etkisi kontrol edilirken pozitif katsayıların anlamı bağımlı değişken üzerinde pozitif etki yaptığı, negatif katsayıların anlamı ise bağımlı değişken üzerinde negatif etki yaptığı anlamına gelir. $\mathrm{Bu}$ durumun tam tersi olarak, ilgili açıklayıcı değişkendeki negatif değişimlerin etkisi kontrol edilirken pozitif katsayıların anlamı bağımlı değişken üzerinde negatif etki yaptığı ve negatif katsayıların anlamı ise bağımlı değişken üzerinde pozitif etki yaptığı anlamına gelir.

Sonuçlar incelendiğinde, Amerikan hisse senedi piyasasındaki gelişmelerin BIST endeksini kısa dönemde pozitif bir şekilde etkilediği ve bu etkilerin asimetrik olduğu gözlemlenmiştir. Kısa dönem pozitif ve negatif katsayıları incelendiğinde gecikme seviyesi 0 iken Amerikan hisse senedi piyasasındaki pozitif gelişmelerin BIST üzerindeki pozitif etkilerinin negatif gelişmelerden kaynaklanan negatif etkilerden daha güçlü olduğu görülmektedir. Fakat, gecikme seviyesi arttıkça Amerikan hisse senedi piyasasındaki negatif gelişmelerin BIST üzerindeki negatif etkilerinin pozitif gelişmelerden kaynaklanan pozitif etkilerden daha güçlü olduğu görülmektedir. Yani günlük veri seti kullanıldığı dikkate alındığında, kısa dönemde Amerikan piyasasına yönelik pozitif algıların BIST getirileri üzerindeki pozitif etkilerinden ziyade Amerikan piyasasında yaşanan olumsuz dalgalanmaların negatif etkilerinin daha baskın olduğu iddia edilebilir. Uzun dönemdeki katsayılar incelendiğinde ise, Amerikan hisse senedi piyasasındaki gelişmelerin BIST 
endeksini negatif bir şekilde etkilediği ve bu etkilerin asimetrik olmadığı gözlemlenmiştir. Yani, Amerikan hisse senedi piyasasındaki pozitif gelişmelerin BIST üzerindeki negatif etkilerinin negatif gelişmelerden kaynaklanan pozitif etkiler ile etkinin büyüklüğü açısından benzer olduğu görülmektedir.

VIX (korku) endeksinin Türkiye hisse senedi piyasası üzerindeki etkileri incelendiğinde oldukça ilginç sonuçlar gözlenmiştir. Wald-test sonuçlarımız VIX endeksinin özellikle uzun dönemde BIST getirileri üzerinde önemli derecede asimetrik etkileri olduğunu ortaya koymuştur. Kısa dönemde VIX endeksindeki bir artışın BIST getirileri üzerinde pozitif ve önemli derecede (özellikle 2. gecikme seviyesinde) etkiler yarattığı görülmüştür. Bununla birlikte kısa dönemde VIX endeksinde görülen azalmanın BIST endeksinin üzerinde istatistiksel olarak önemli derecede etkisi olmadığı gözlemlenmiştir. Uzun dönemde ise bu durumun tam tersi bir durum geçerlidir. Yani, uzun dönemde VIX endeksinde görülen artışın herhangi bir etkisi ortaya konamazken, bu endekteki azalmanın BIST getirileri üzerinde azalma etkisine neden olduğu görünmektedir. Özellikle katsayıların büyüklüğü ve asimetrik etkilerin istatistiksel önemine bakarak k1sa dönem ile karşılaştırıldığında, uzun dönemde VIX (korku) endeksindeki azalmanın BIST üzerindeki negatif etkileri yatırım stratejileri belirleme açısından oldukça önemli bir bulgudur.

ABD merkez bankası (FED) para politikasındaki belirsizliğin (TYVIX) BIST endeksi üzerindeki etkilerine bakıldığında kısa dönemde oldukça güçlü asimetrik etkilerin olduğu görülmektedir. Kısa dönemde FED'in para politikasındaki belirsizliğindeki artışın BIST endeksi üzerinde önemli derecede herhangi bir etkisi görülmemektedir. Fakat yine kısa dönemde FED’in para politikası belirsizliğindeki azalışın BIST endeksi üzerinde pozitif bir etkisi olduğu görülmektedir. Bu sonuç bize kısa dönemde FED politikalarındaki belirsizlik azaldığında Türkiye hisse senedi piyasasına yatırım eğiliminin güçlendiğini göstermektedir. Diğer taraftan, uzun dönemde Wald-test sonucunda ortaya konan olasılık değeri oldukça marjinal seviyede görünmesine rağmen, katsayıların istatistiksel önemine bakıldığında FED politikalarındaki belirsizliğin azalışından ziyade artışının etkili olduğu görülmektedir. Uzun dönemde FED politikalarındaki belirsizliğin artışının BIST endeksi üzerinde önemli derecede negatif etkileri olacağı sonucuna ulaşılmıştır.
Tablo 4. NARDL Tahmin Sonuçları (Bağımlı Değişken: $\triangle$ LTUR $_{\mathrm{t}}$ )

\begin{tabular}{|c|c|c|c|c|}
\hline \multicolumn{5}{|c|}{ Panel A. Tahmin Edilen Katsayılar } \\
\hline $\mathrm{AD}$ & Katsayı & $\begin{array}{c}\text { Standart } \\
\text { Hata } \\
\end{array}$ & t-istatistiği & Olasilik \\
\hline $\mathrm{C}$ & 0.08435 & 0.02360 & 3.57453 & 0.00040 \\
\hline LTUR $_{t-1}$ & -0.01428 & 0.00377 & -3.78372 & 0.00020 \\
\hline $\operatorname{LUSA}_{\mathrm{t}-1}{ }^{+}$ & -0.03804 & 0.01786 & -2.13057 & 0.03320 \\
\hline $\operatorname{LUSA}_{\mathrm{t}-1}{ }^{-}$ & -0.04141 & 0.01647 & -2.51442 & 0.01200 \\
\hline $\operatorname{LVIX}_{\mathrm{t}-1}{ }^{+}$ & 0.00043 & 0.00288 & 0.15009 & 0.88070 \\
\hline $\operatorname{LVIX}_{\mathrm{t}-1}{ }^{-}$ & 0.00665 & 0.00333 & 1.99831 & 0.04580 \\
\hline LTYVIX $_{\mathrm{t}-1}^{+}$ & -0.00737 & 0.00308 & -2.38977 & 0.01700 \\
\hline LTYVIX $_{t-1}^{-}$ & -0.00343 & 0.00355 & -0.96851 & 0.33290 \\
\hline$\triangle \mathrm{LUSA}_{\mathrm{t}}^{+}$ & 0.71165 & 0.13526 & 5.26143 & 0.00000 \\
\hline$\triangle \mathrm{LUSA}_{\mathrm{t}-1}{ }^{+}$ & 0.18980 & 0.09324 & 2.03551 & 0.04190 \\
\hline$\triangle \mathrm{LUSA}_{\mathrm{t}}^{-}$ & 0.55716 & 0.16326 & 3.41263 & 0.00070 \\
\hline$\triangle \operatorname{LUSA}_{\mathrm{t}-1}^{-}$ & 0.37951 & 0.14611 & 2.59749 & 0.00950 \\
\hline$\triangle$ LUSA $_{\mathrm{t}-2}^{-}$ & 0.43012 & 0.14747 & 2.91670 & 0.00360 \\
\hline$\triangle$ LUSA $_{\mathrm{t}-3}^{-}$ & 0.30913 & 0.12493 & 2.47439 & 0.01340 \\
\hline$\triangle \mathrm{LVIX}_{\mathrm{t}}^{+}$ & -0.01375 & 0.01840 & -0.74720 & 0.45500 \\
\hline$\triangle \mathrm{LVIX}_{\mathrm{t}-1}{ }^{+}$ & 0.01962 & 0.01417 & 1.38475 & 0.16630 \\
\hline$\triangle \mathrm{LVIX}_{\mathrm{t}-2}{ }^{+}$ & 0.04063 & 0.01359 & 2.99074 & 0.00280 \\
\hline$\Delta \mathrm{LVIX}_{\mathrm{t}-3}{ }^{+}$ & 0.02616 & 0.01410 & 1.85541 & 0.06370 \\
\hline$\triangle \mathrm{LVIX}_{\mathrm{t}}^{-}$ & 0.02251 & 0.01524 & 1.47646 & 0.14000 \\
\hline$\triangle$ LTYVIX $_{\mathrm{t}}^{+}$ & -0.03353 & 0.02057 & -1.62957 & 0.10340 \\
\hline$\triangle$ LTYVIX $_{\mathrm{t}}^{-}$ & -0.06069 & 0.01432 & -4.23989 & 0.00000 \\
\hline$\underset{1}{\triangle \text { LTYVIX }_{\mathrm{t}-}}$ & -0.04493 & 0.01651 & -2.72190 & 0.00650 \\
\hline $\begin{array}{c}\triangle \mathrm{LTYVIX}_{\mathrm{t}-} \\
2^{-}\end{array}$ & -0.00520 & 0.01367 & -0.38035 & 0.70370 \\
\hline $\begin{array}{c}\triangle \mathrm{LTYVIX}_{\mathrm{t}-} \\
3^{-}\end{array}$ & -0.02186 & 0.01464 & -1.49392 & 0.13540 \\
\hline $\begin{array}{c}\triangle \mathrm{LTYVIX}_{\mathrm{t}-} \\
4\end{array}$ & -0.03506 & 0.01509 & -2.32250 & 0.02030 \\
\hline Trend & 0.00024 & 0.00009 & 2.53730 & 0.01120 \\
\hline \multicolumn{5}{|c|}{ Panel B. Uzun Dönem Katsayılar } \\
\hline LUSA $^{+}$ & $-2.640431^{*}$ & LUSA $^{-}$ & $\begin{array}{c}2.879714^{*} \\
*\end{array}$ & \\
\hline LVIX $^{+}$ & 0.039627 & LVIX $^{-}$ & $0.475539 *$ & \\
\hline LTYVIX $^{+}$ & $0.519406 * *$ & LTYVIX & -0.23993 & \\
\hline
\end{tabular}

Not: AD açıklayıcı değişkenleri ifade eder. Newey-West (1987) tahmincisi kullanılarak hesaplanan tutarlı standart hatalar ve t-istatistikler sunulmuştur. LTUR, LUSA, LVIX ve LTYVIX değişkenleri sırasıyla çalışmamızda kullanılan Türkiye ve ABD hisse senedi piyasaları endeksleri ile VIX ve TYVIX endekslerinin logaritmik olarak ifade edilmiş formunu temsil etmektedir. LUSA $^{+}$, LUSA, LVIX $^{+}$LVIX, LTYVIX $^{+}$, ve LTYVIX ${ }^{-}$ilgili değişkenlere ait pozitif ve negatif değişiklikler ile ilgili uzun dönem katsayılarını göstermektedir. $\triangle$ birinci fark operatörünü temsil eder. Üstsimgeler $*$ ve $* *$ sirasiyla $\% 10$ ve $\% 5$ düzeyinde anlamlılığ göstermektedir. $\beta^{+}=\left(-\omega_{j}^{+} / \chi\right)$ ve $\beta=\left(-\omega_{j}^{-} / \chi\right)$ denklem 13'deki ilgili bağımsız değişkenlere ait (LUSA ${ }^{+}, \mathrm{LUSA}^{-}, \mathrm{LVIX}^{+}$ LVIX, $^{-}$LTYVIX $^{+}$, ve LTYVIX), tüm $\mathrm{j}=1,2$, ve 3 için, pozitif ve negatif değişiklikler ile ilgili uzun dönem katsayılarının nasıl hesaplandığını ifade etmektedir. 
Tablo 5. Wald-test Sonuçları

\begin{tabular}{|c|c|c|c|}
\hline \multicolumn{4}{|c|}{ Panel A. Uzun Dönem Simetri } \\
\hline Bağımlı Değişken & $\mathrm{W}_{\mathrm{LR}}($ LUSA $)$ & $\mathrm{W}_{\mathrm{LR}}(\mathrm{LVIX})$ & $\mathrm{W}_{\mathrm{LR}}($ LTYVIX $)$ \\
\hline DLTUR & $\begin{array}{r}0.712643 \\
{[0.3987]}\end{array}$ & $\begin{array}{c}10.17821 * * * \\
{[0.0014]}\end{array}$ & $\begin{array}{l}1.490659 \\
{[0.2223]}\end{array}$ \\
\hline \multicolumn{4}{|c|}{ Panel B. Kısa Dönem Simetri } \\
\hline Bağımlı Değişken & $\mathrm{W}_{\mathrm{SR}}($ LUSA $)$ & $\mathrm{W}_{\mathrm{SR}}(\mathrm{LVIX})$ & $\mathrm{W}_{\mathrm{SR}}($ LTYVIX $)$ \\
\hline DLTUR & $\begin{array}{c}4.831294 * * \\
{[0.0281]}\end{array}$ & $\begin{array}{c}3.229486^{*} \\
{[0.0725]}\end{array}$ & $\begin{array}{c}11.51007^{* * * *} \\
{[0.0007]}\end{array}$ \\
\hline \multicolumn{4}{|c|}{$\begin{array}{l}\text { Not: } \mathrm{W}_{\mathrm{LR}} \text { (LUSA), } \mathrm{W}_{\mathrm{LR}} \text { (LVIX), ve } \mathrm{W}_{\mathrm{LR}} \text { (LTYVIX) ilgili değiskenler ile } \\
\text { ilgili uzun dönem simetri testi sonuçlarını ifade etmektedir. } \mathrm{W}_{\mathrm{SR}} \text { (LUSA), } \\
\mathrm{W}_{\mathrm{SR}} \text { (LVIX), ve } \mathrm{W}_{\mathrm{SR}} \text { (LTYVIX) ilgili değişkenler ile ilgili kısa dönem } \\
\text { simetri testi sonuçlarını ifade etmektedir. Üstsimgeler *** ve *** } \\
\text { sirasıly \% } \% \text {, \%5 ve \%1 düzeyinde anlamlılığı göstermektedir. }\end{array}$} \\
\hline
\end{tabular}

\section{Sonuç ve Tartışma}

Global piyasalardaki ani değişikliklerin yönü (pozitif veya negatif gelişmeler) piyasa oyuncularının çeşitli finansal varlıkların yatırım potansiyeli hakkındaki fikirlerini ve dolayısıyla piyasalardaki risk iştahını önemli ölçüde etkileyebilir. Dolayısı ile piyasalar arasındaki dinamik ve asimetrik etkileşimlerin incelenmesi yatırımcıların risk algılarının nasıl değiştiğine dair önemli çıkarımlarda bulunmamıza yardımcı olur. Bu bağlamda, piyasalar ve makroekonomik göstergelerdeki pozitif ve negatif değişimlerin etkilerini dikkate almak son derece önemlidir. Gelişmiş piyasalar ile kıyaslandığında, daha riskli karakteristiklere sahip olan gelişmekte olan piyasalara olan fon akışının sürekliliğinin sağlanabilmesi için global yatırımcıların risk iştahının yüksek seviyelerde olması gerekmektedir. Bu çalışmada, ABD hisse senedi piyasası ve bu piyasadaki belirsizliklerin yanında $\mathrm{ABD}$ merkez bankası (FED) para politikasındaki belirsizliğin Türkiye hisse senedi piyasası (BIST) üzerindeki etkileri doğrusal (simetrik) ve doğrusal olmayan (asimetrik) otoregresif gecikmesi dağıtılmış (ARDL ve NARDL) modeller kullanılarak incelenmiştir. Çalışmanın bulguları Türkiye hisse senedi piyasasının ABD piyasalarındaki gelişmeler ve belirsizliklerin yönüne (pozitif veya negatif) oldukça duyarlı olduğunu göstermektedir. Bu duyarlılık kısa ve uzun dönemde oldukça farklılaşma göstermektedir. Özetle, bu çalışma Türkiye hisse senedi piyasasının yatırım potansiyeline dair önemli bulgular sunmakta ve bu bulgular global yatıımcıların Borsa İstanbul (BIST) hakkında nasıl bir risk algısına sahip olduğuna dair önemli çıkarımlar içermektedir.

Yapılan analizler sonucu elde edilen bulgulara bakıldığında, Amerikan hisse senedi piyasasındaki gelişmelerin kısa dönemde BIST endeksini istatistiksel olarak önem seviyesinde asimetrik ve pozitif bir şekilde etkilediği görülmüştür. Elde edilen katsayılar incelendiğinde, kısa dönemde Amerikan hisse senedi piyasasındaki pozitif gelişmelerin BIST üzerindeki pozitif etkilerinden ziyade negatif gelişmelerden kaynaklanan BIST üzerindeki negatif etkilerin gecikme seviyeleri arttıkça daha önemli olduğu görülmektedir. Uzun dönemde ise Amerikan hisse senedi piyasasının asimetrik olmayan ve negatif bir şekilde BIST endeksi üzerinde etkili olduğu görülmüştür. Yani ABD hisse senedi piyasa endeksindeki artışların yaratacağ 1 negatif etki ile azalışların yaratacağ yukarı birbirine eşittir. Bu sonuçlar, kısa dönemden ziyade, uzun dönemde Türkiye hisse senedi piyasasına yatırım yapmaya yönelik stratejilerin portföy çeşitlendirme stratejileri açısından daha etkin stratejiler olacağını göstermektedir. Özetle, yapılan analizler sonucunda elde edilen bulgular uzun dönemde BIST'in, ABD piyasalarının global piyasaları yönlendirici etkisi dikkate alındığında, ABD hisse senedi piyasası düşüş trendine girdiğinde global yatırımcılar için oldukça çekici bir piyasa olduğu sonucunu ortaya koymaktadır.

Bu çalışmada, ABD piyasalarındaki belirsizliklerin BIST üzerindeki etkilerine dair çok önemli sonuçlar ortaya konmuştur. VIX (korku) endeksinin BIST endeksi üzerindeki asimetrik etkilerinin önemi ve katsayllar incelendiğinde, kısa döneme kıyasla, uzun dönemde VIX (korku) endeksindeki azalmanın BIST üzerindeki negatif etkileri BIST hisselerinin getiri performanlarını değerlendirme açısından oldukça ilginç ve çarpıcı bir bulgudur. Bu bulgudan hareketle Amerikan hisse senedi piyasasında belirsizliklerin azalması ile yatırımcıların Türkiye hisse senedi piyasası gibi riskli piyasalardan çekilip gelişmiş piyasalara yatırım yapma eğilimi göstereceği sonucuna ulaşlabilir. Bunun nedeni böyle dönemlerde gelişmiş piyasalarda daha az risk ile daha fazla getiri elde edilebilmesi olasıllığı olabilir.

ABD merkez bankasının para politikasında yapacağ 1 değişikliğe dair belirsizliklerin etkisine bakıldığında ise, kısa dönemde FED politikalarındaki belirsizlik azaldığında Türkiye hisse senedi piyasası yatırım potansiyelinde bir artış görülürken, uzun dönemde FED politikalarındaki belirsizliğin artışının BIST endeksi üzerindeki olumsuz yansımaları nedeniyle BIST hisselerine yatırım eğiliminin azaldığı gözlemlenmektedir. Bu bulgular bize FED'in gelecekteki olası politika değişikliklerinin (faiz artış veya azalışı) ve bu değişikliklerin zamanlamasına dair öngörülerin Türkiye gibi gelişmekte olan piyasalara yönelik risk algisinı ve dolayisiyla bunun sonucu olarak global yatırımcıların risk iştahlarını nasıl şekillendirdiğini göstermektedir. FED politikalarındaki belirsizlik artışı döviz kurlarında önemli miktarda dalgalanmalara (artan volatiliteye) neden olarak özellikle gelişmekte olan piyasalara yönelik yatırımlarda endişenin artmasına neden olmaktadır. $\mathrm{Bu}$ açıdan bakıldığında, özellikle uzun dönemde, BIST hisselerinin FED politikalarındaki belirsizliğe olan duyarlılı̆̆ını azaltabilmek için Türkiye Cumhuriyet Merkez Bankasının (TCMB) politika araçlarını doğru zamanda ve etkin bir şekilde kullanacağ 1 algısını güçlendirerek global piyasa oyuncularına güven verilmesi gerekmektedir.

\section{Kaynakça}

Acemoglu, D., \& Scott, A. (1997). Asymmetric business cycles: Theory and time-series evidence. Journal of Monetary Economics, 40(3), 501-533. 
Aloui, R., Aïssa, M. S. B., \& Nguyen, D. K. (2011). Global financial crisis, extreme interdependences, and contagion effects: The role of economic structure? Journal of Banking \& Finance, 35(1), 130-141.

Ang, A., Hodrick, R. J., Xing, Y., \& Zhang, X. (2006). The cross-section of volatility and expected returns. The Journal of Finance, 61(1), 259-299.

Baker, S. R., Bloom, N., \& Davis, S. J. (2016). Measuring economic policy uncertainty. The Quarterly Journal of Economics, 131(4), 1593-1636.

Başarır, Ç. (2018). Korku Endeksi (VIX) ile BIST 100 Arasındaki İlişki: Frekans Alanı Nedensellik Analizi. Dokuz Eylül Üniversitesi İşletme Fakültesi Dergisi, 19(2), 177-191.

Becker, R., Clements, A. E., \& McClelland, A. (2009). The jump component of S\&P 500 volatility and the VIX index. Journal of Banking \& Finance, 33(6), 10331038 .

Bekaert, G., \& Harvey, C. R. (1995). Time-varying world market integration. The Journal of Finance, 50(2), 403444.

Bessler, D. A., \& Yang, J. (2003). The structure of interdependence in international stock markets. Journal of International Money and Finance, 22(2), 261-287.

Blair, B. J., Poon, S. H., \& Taylor, S. J. (2001). Forecasting S\&P 100 volatility: the incremental information content of implied volatilities and high-frequency index returns. Journal of Econometrics, 105(1), 5-26.

Bloom, N. (2014). Fluctuations in uncertainty. Journal of Economic Perspectives, 28(2), 153-76.

Carrieri, F., Errunza, V., \& Hogan, K. (2007). Characterizing world market integration through time. Journal of Financial and Quantitative Analysis, 42(4), 915-940.

Chicago Board Options Exchange (2015). Guide to the CBOE / CBOT 10 Year Treasury Note Volatility Index (TYVIXSM Index). (Erişim: 03/03/2019), http://www.cboe.com/micro/volatility/tyvix/pdf/tyvixgu idepart1.pdf

Cho, D. C., Eun, C. S., \& Senbet, L. W. (1986). International arbitrage pricing theory: An empirical investigation. The Journal of Finance, 41(2), 313-329.

Chowdhury, A. R. (1994). Stock market interdependencies: evidence from the Asian NIEs. Journal of Macroeconomics, 16(4), 629-651.

Dickey, D. A., \& Fuller, W. A. (1979). Distribution of the estimators for autoregressive time series with a unit root. Journal of the American Statistical Association, 74(366a), 427-431.

Eren, M., \& Başar, S. (2016). Makroekonomik Faktörler Ve Kredi Temerrüt Takaslarının BIST-100 Endeksi Üzerindeki Etkisi: Ardl Yaklaşımı. Ataturk University Journal of Economics \& Administrative Sciences, 30(3).

Fong, W. M., Wong, W. K., \& Lean, H. H. (2005). International momentum strategies: a stochastic dominance approach. Journal of Financial Markets, 8(1), 89-109.

Granger, C. W., \& Yoon, G. (2002). Hidden cointegration. U of California, Economics Working Paper, (2002-02).

Hatipoğlu, M., \& Tekin, B. (2017). The Effects of VIX Index, Exchange Rate \& Oil Prices on the BIST 100 Index: A Quantile Regression Approach. Ordu Üniversitesi Sosyal Bilimler Araştırmaları Dergisi, 7(3), 627-634.

Hoffmann, A. O., Post, T., \& Pennings, J. M. (2013). Individual investor perceptions and behavior during the financial crisis. Journal of Banking \& Finance, 37(1), 60-74.

Kahneman, D., \& Tversky, A. (1979). Prospect Theory: An Analysis of Decision under Risk. Econometrica, 47(2), 263-292.

Karğın, S., Kayalıdere, K., Güleç, T. C., \& Erer, D. (2018). Spillovers Of Stock Return Volatility To Turkish Equity Markets From Germany, France, And America. Dokuz Eylul University Journal of Graduate School of Social Sciences, 20(2), 171-187

Kaya, E. (2015). Borsa İstanbul (BIST) 100 endeksi ile Zımni Volatilite (VIX) endeksi arasındaki eşbütünleşme ve Granger nedensellik. Karamanoğlu Mehmetbey Üniversitesi Sosyal Ve Ekonomik Araştırmalar Dergisi, 2015(1), 1-6.

Kocaarslan, B., Sari, R., \& Soytas, U. (2017). Are there any diversification benefits among global finance center candidates in Eurasia?. Emerging Markets Finance and Trade, 53(2), 357-374.

Korkmaz, T., \& Çevik, E. İ. (2009). Zımni Volatilite Endeksinden Gelişmekte Olan Piyasalara Yönelik Volatilite Yayılma Etkisi. BDDK Bankacilik ve Finansal Piyasalar, 3(2), 87-105.

Kumar, M. S., \& Persaud, A. (2002). Pure contagion and investors' shifting risk appetite: analytical issues and empirical evidence. International Finance, 5(3), 401436.

Küçükkaya, E. (2009). Diversification benefits of including Turkish and US stocks in a portfolio. The International Journal of Economic and Social Research,. 5(2), 1-11.

Maki, D. (2012). Tests for cointegration allowing for an unknown number of breaks. Economic Modelling, 29(5), 2011-2015.

Newey, W.K., \& West, K.D., (1987). A simple, positive semi-definite, heteroskedasticity and autocorrelation consistent covariance matrix. Econometrica, 55 (3), 703-708.

Olgun, H., \& Ozdemir, Z. A. (2008). Linkages between the center and periphery stock prices: Evidence from the vector ARFIMA model. Economic Modelling, 25(3), 512-519.

Öner, H., İçellioğlu, C. Ş., \& Öner, S. (2018). Volatilite Endeksi (VIX) ile Gelişmekte Olan Ülke Hisse Senedi Piyasası Endeksleri Arasındaki Engel-Granger Eş- 
Bütünleşme ve Granger Nedensellik Analizi. Finansal Araştırmalar ve Çalışmalar Dergisi, 10(18), 110-124.

Pesaran, M. H., \& Shin, Y. (1998). An autoregressive distributed-lag modelling approach to cointegration analysis. Econometric Society Monographs, 31, 371413.

Pesaran, M. H., Shin, Y., \& Smith, R. J. (2001). Bounds testing approaches to the analysis of level relationships. Journal of Applied Econometrics, 16(3), 289-326.

Phillips, P.C.B., \& Perron, P., (1988). Testing for a unit root in time series regressions. Biometrica 75 (2), 335346.

Sadeghzadeh, K., \& Elmas, B. (2018). Makroekonomik Faktörlerin Hisse Senedi Getirilerine Etkilerinin BIST'de Araștırılması. Muhasebe ve Finansman Dergisi, (80), 207-232.
Schorderet, Y., (2003). Asymmetric Cointegration. University of Geneva, Mimeo.

Shin, Y., Yu, B., \& Greenwood-Nimmo, M. (2014). Modelling asymmetric cointegration and dynamic multipliers in a nonlinear ARDL framework. In Festschrift in honor of Peter Schmidt (pp. 281-314). Springer, New York, NY.

Solnik, B. H. (1974). Why Not Diversify Internationally Rather Than Domestically?. Financial Analysts Journal, 30(4), 48-54.

Toda, H. Y., \& Yamamoto, T. (1995). Statistical inference in vector autoregressions with possibly integrated processes. Journal of Econometrics, 66(1-2), 225-250.

Zeren, F., \& Koç, M. (2013). Analyzing Integration between Stock Market of Turkey and G8 Nations with Maki Cointegration Test. Journal of Applied Finance and Banking, 3(6), 135. 